\title{
BMJ Open Clustering of risk factors and the risk of incident cardiovascular disease in Asian and Caucasian populations: results from the Asia Pacific Cohort Studies Collaboration
}

To cite: Peters SAE, Wang $X$ Lam T-H, et al. Clustering of risk factors and the risk of incident cardiovascular disease in Asian and Caucasian populations: results from the Asia Pacific Cohort Studies Collaboration. BMJ Open 2018;8:e019335. doi:10.1136/ bmjopen-2017-019335

- Prepublication history and additional material for this paper are available online. To view these files, please visit the journal online (http://dx.doi. org/10.1136/bmjopen-2017019335).

Received 29 August 2017 Revised 1 December 2017 Accepted 22 January 2018
Check for updates

For numbered affiliations see end of article.

Correspondence to Professor Mark Woodward; markw@georgeinstitute.org.au

\section{ABSTRACT}

Objective To assess the relationship between risk factor clusters and cardiovascular disease (CVD) incidence in Asian and Caucasian populations and to estimate the burden of CVD attributable to each cluster.

Setting Asia Pacific Cohort Studies Collaboration. Participants Individual participant data from 34 population-based cohorts, involving 314024 participants without a history of CVD at baseline.

Outcome measures Clusters were 11 possible combinations of four individual risk factors (current smoking, overweight, blood pressure (BP) and total cholesterol). Cox regression models were used to obtain adjusted HRs and 95\% Cls for CVD associated with individual risk factors and risk factor clusters. Populationattributable fractions (PAFs) were calculated.

Results During a mean follow-up of 7 years, 6203 CVD events were recorded. The ranking of $\mathrm{HRs}$ and PAFs was similar for Australia and New Zealand (ANZ) and Asia; clusters including BP consistently showed the highest HRs and PAFs. The BP-smoking cluster had the highest HR for people with two risk factors: 4.13 (3.56 to 4.80) for Asia and 3.07 (2.23 to 4.23) for ANZ. Corresponding PAFs were $24 \%$ and $11 \%$, respectively. For individuals with three risk factors, the BP-smoking-cholesterol cluster had the highest HR (4.67 (3.92 to 5.57) for Asia and 3.49 (2.69 to 4.53) for ANZ). Corresponding PAFs were $13 \%$ and $10 \%$. Conclusions Risk factor clusters act similarly on CVD risk in Asian and Caucasian populations. Clusters including elevated BP were associated with the highest excess risk of CVD.

\section{INTRODUCTION}

Cardiovascular disease (CVD) is the main contributor to morbidity and mortality worldwide and over $80 \%$ of CVD deaths take place in low-income and middle-income countries. ${ }^{1}$ Much of the burden of CVD is modifiable by adequate control

\section{Strengths and limitations of this study}

- Strengths of this study are the large sample size, prospective design and the inclusion of studies among diverse populations across the Asia-Pacific region.

- We did not have sufficient cardiovascular disease (CVD) events to allow for the reliable quantification of associations between risk factor clusters and the risk of major subtypes of CVD, such as coronary heart disease and stroke, or sex-specific effects within regions.

- Most cohorts included in the Asia Pacific Cohort Studies Collaboration were initiated around 20 years ago, before the epidemiological transition during the past few decades in Asia.

of a set of key risk factors: elevated blood pressure, cigarette smoking, elevated blood lipids, excess body weight and diabetes. ${ }^{23}$ The Global Burden of Disease study showed that each of these individual cardiovascular risk factors were among the top 10 causes of loss of disability-adjusted life years. ${ }^{4}$ Large international case-control studies, INTERHEART $^{2}$ and INTERSTROKE, ${ }^{3}$ have quantified the individual contribution of these risk factors to CVD and highlighted the substantial geographic variation in the burden of CVD attributable to particular risk factors. For instance, abdominal obesity was a great contributor to CVD risk in Western Europe, North America and South-East Asia, while it was a smaller contributor in China. ${ }^{23}$

Cardiovascular risk factors cluster within individuals and clustering of risk factors has been associated with a higher risk of CVD. ${ }^{56}$ Hence, information on the risks 
associated with clusters is relevant for targeting prevention, management and treatment strategies. This is particularly of relevance for Asia, as region where the burden of CVD is still rising, yet where data on the burden of risk factor clusters are limited.

The Asia Pacific Cohort Studies Collaboration (APCSC) has conducted a series of studies to evaluate the joint effects of two risk factors (combinations of excess body weight, elevated systolic blood pressure (SBP), elevated total cholesterol, diabetes and cigarette smoking) and to compare the effects in Asian and Caucasian populations. ${ }^{7-16}$ Although several national and international guidelines on cardiovascular risk factor management use sets of individual risk factors to estimate the absolute 10-year risk, direct comparisons of risk factor clusters have not been made nor have clusters with more than two risk factors been analysed in APCSC. Therefore, the aim of the present study was to assess the relationship between multiple risk factor clusters and the risk of CVD in Asian and Caucasian populations and to estimate the burden of CVD attributable to each of these clusters.

\section{METHODS}

The APCSC is an individual participant data overview comprising 44 cohort studies in the Asia Pacific region. Details of the APCSC, and characteristics of the included studies have been described previously. ${ }^{17}$ Studies from mainland China, Hong Kong, Japan, Korea, Singapore, Taiwan or Thailand were classified as Asian, while studies from Australia and New Zealand (ANZ) were classified as Caucasian. For the present study, only those studies with information on smoking status, blood pressure, total cholesterol and body mass index (BMI) were included (34 studies). The prevalence of diabetes was relatively low in the included studies $(6 \%$ in Asia, and $4 \%$ in ANZ), which can in part be explained by the inclusion of studies that conducted their baseline surveys before the rapid rise in the prevalence of diabetes. For that reason, clusters with diabetes were not included. Participants with known coronary heart disease (CHD) and stroke at baseline were excluded. The primary study outcome was the incidence of fatal or non-fatal CVD (International Classification of Diseases Ninth Revision 410-414, 430-438).

\section{Cardiovascular risk factors}

Methods of measurement of baseline risk factors have been described previously. ${ }^{17}$ Smoking status was determined from self-report questionnaires. BMI was calculated from measured body weight (in kilograms) divided by measured height (in metres) squared. Overweight was defined as a BMI $\geq 25 \mathrm{~kg} / \mathrm{m}^{2}{ }^{18}$ Elevated blood pressure was defined as SBP $\geq 140 \mathrm{~mm} \mathrm{Hg}$ or diastolic blood pressure $\geq 90 \mathrm{~mm} \mathrm{Hg},{ }^{19}$ and elevated cholesterol was defined as total cholesterol $\geq 5.2 \mathrm{mmol} / \mathrm{L}$. ${ }^{20}$

\section{Statistical analyses}

HRs and 95\% CIs for different risk factor clusters were estimated from Cox proportional hazards regression models. The models were adjusted for age and stratified by sex and study. To facilitate comparisons, we also assessed the corresponding associations for individual risk factors. The reference group consisted of individuals without any of the four risk factors. The population attributable fractions (PAFs) for CVD due to risk factor clusters were calculated using the observed prevalence estimates and the HRs as described above. The formula was $^{21}$ :

$$
\frac{\text { prevalence* }(H R-1)}{1+\text { prevalence } *(H R-1)}
$$

Risk factor clusters were mutually exclusive in calculating the HRs, but were not mutually exclusive in calculating the PAFs. Prevalences and PAFs were estimated separately by region, and, in secondary analyses, by sex. As a sensitivity analysis, individuals with a history of diabetes were excluded.

\section{RESULTS}

\section{Baseline characteristics}

Overall, 314024 individuals were included in the analyses, of whom $74 \%$ were from Asia, and $59 \%$ were men (table 1 and online supplementary etable 1 ). Participants in Asia were 4 years younger (mean age, 47 years) than those in ANZ. Caucasian participants had higher levels of BMI, SBP and total cholesterol. Smoking was more common in Asian participants, which was due to high smoking rates in men.

\section{Risk factors and risk factor clusters and in relation to cardiovascular events}

During a mean follow-up of 7 years, 6203 CVD events were recorded. The ranking of HRs by individual risk factors and risk factor clusters was similar in ANZ and Asia (figure 1 and table 2). The blood pressuresmoking cluster had the highest HR in people with two risk factors (HR (95\% CI): 4.13 (3.56 to 4.80) in Asia and 3.07 (2.23 to 4.23) in ANZ and the cholesteroloverweight cluster had the lowest HR: 1.25 (0.94 to 1.65 ) in Asia and 1.79 (1.39 to 2.29) in ANZ. For individuals with three risk factors, the blood pressuresmoking-cholesterol cluster had the highest (HR 4.67 (3.92 to 5.57) in Asia and 3.49 (2.69 to 4.53) in ANZ; the smoking-cholesterol-overweight cluster had the lowest HR (2.00 (1.51 to 2.67) in Asia and 3.30 (2.51 to $4.35)$ in ANZ). HRs in individuals with four risk factors were 5.66 (4.61 to 6.95) in Asia and 4.35 (3.38 to 5.59) in ANZ. Rankings of HRs were broadly similar between sexes (figure 2 and table 2).

\section{Prevalence and PAFs}

The prevalence of individual risk factors and risk factor clusters and associated PAFs are shown in table 2, figure 3 and online supplementary etable 2. Clusters 
i்

$\sum^{\infty}$

jై

ำ

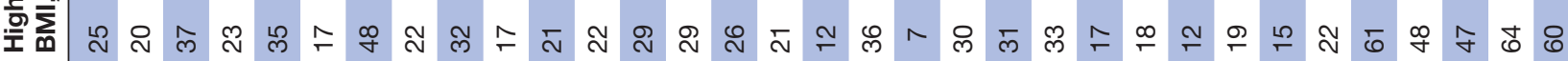

מת

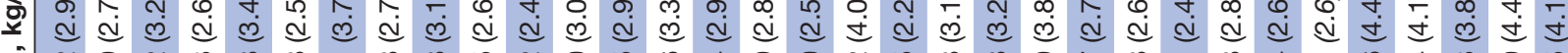

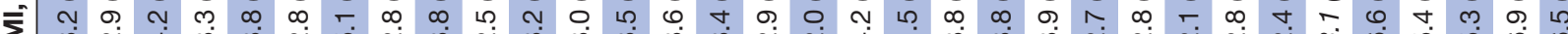

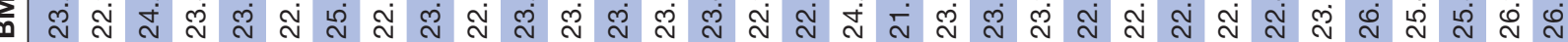

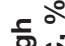

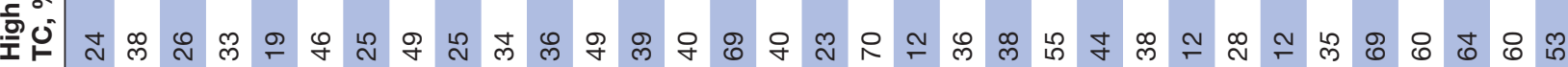

흔

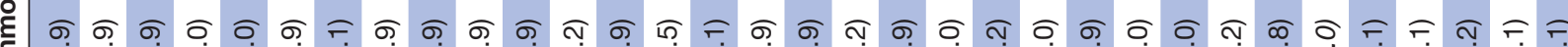

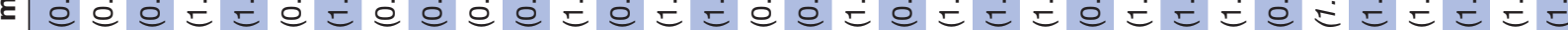

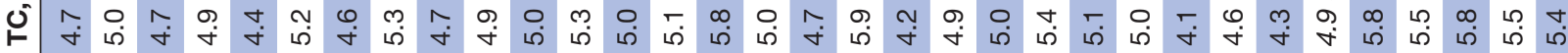

흘

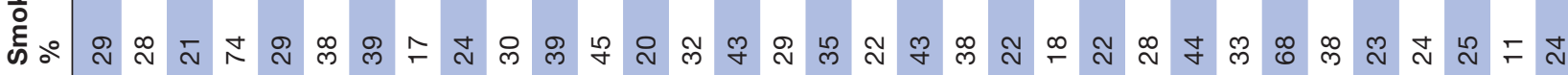
高

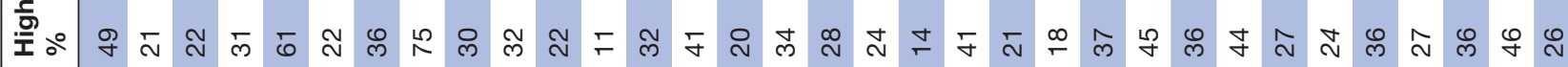

옫

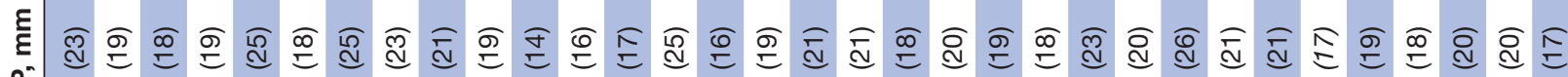

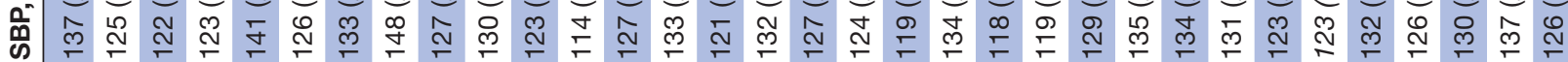

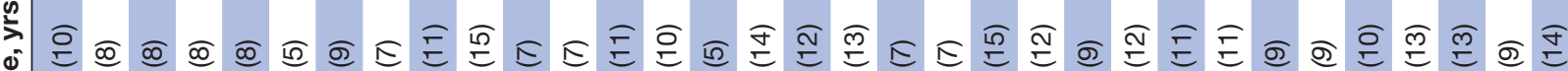

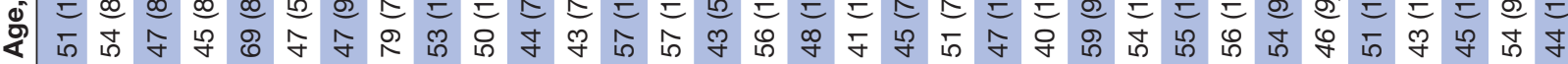

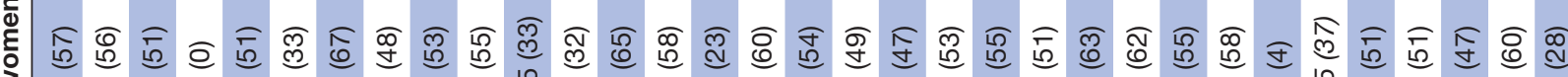

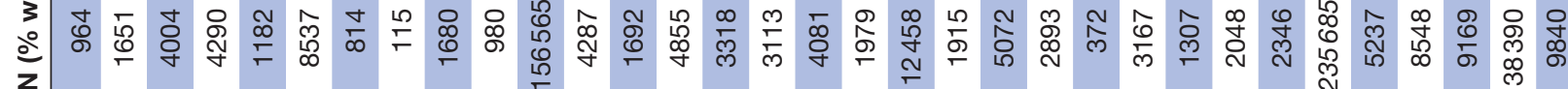

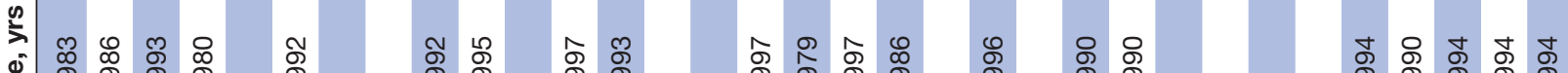

:

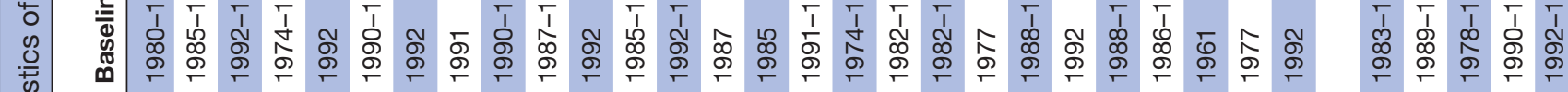

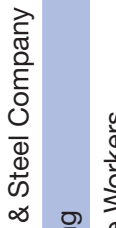

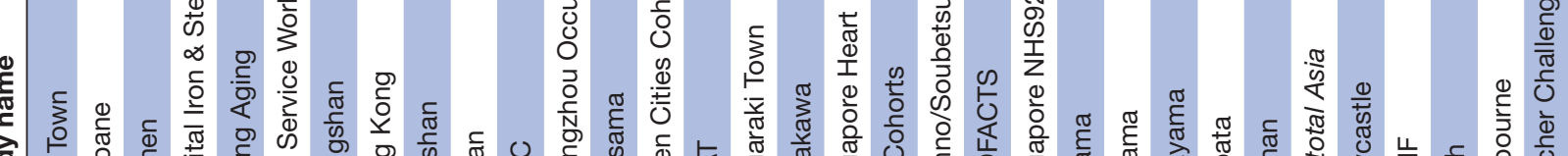

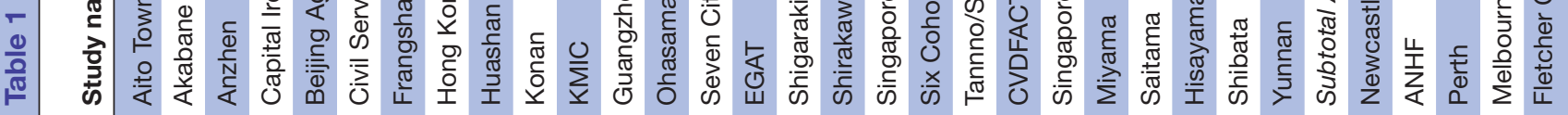




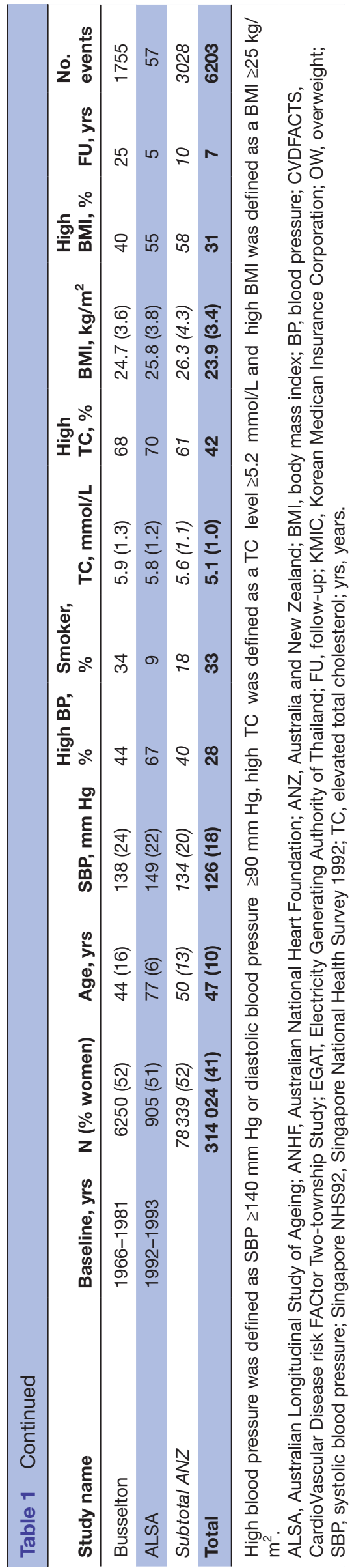

including smoking had the highest PAFs in Asian men, with a PAF of $37 \%$ for the blood pressure-smoking cluster. The blood pressure-cholesterol cluster had the highest PAF in men in ANZ (30\%), followed by the blood pressure-overweight $(28 \%)$, and smokingcholesterol (20\%) clusters. The blood pressure-cholesterol and blood pressure-overweight clusters had the highest PAFs in women in both regions; the PAFs were $17 \%$ and $13 \%$ in Asian women and $36 \%$ and $34 \%$ in women from ANZ. The prevalence of smoking in Asian women is very low, which explains the comparatively low PAFs for risk factor clusters involving smoking.

The main findings did change minimally after exclusion of individuals with a history of diabetes (online supplementary etables 3 and 4 ).

\section{DISCUSSION}

This study of over 320000 individuals in the Asia-Pacific region found that the ranking of the relations between clusters of major modifiable risk factors for CVD and risk of cardiovascular events was similar in Asia and ANZ. In both regions, the greatest excess risks of CVD were found in clusters involving elevated blood pressure. However, differences in the prevalence of risk factors between sexes and regions led to variation in the burden of CVD attributable to risk factor clusters.

The present study is the first to examine the relationships between clusters of two, three or four risk factors and cardiovascular events. We confirm that all combinations of risk factors are related to an increased risk of CVD, and that the risk increases in the presence of additional risk factors. Through direct comparisons, we identified that the most hazardous clusters for CVD where those that included high blood pressure. Furthermore, we expanded the evidence by showing that clusters act broadly similar on the risk of CVD in Asian and Caucasian populations.

High blood pressure, smoking, unfavourable lipid levels, high BMI and diabetes are each independently related to an increased risk of CVD, and the more risk factors are present in an individual, the higher these risks are. Previous reports from the APCSC on the joint effects of several combinations of two risk factors broadly showed that the risk of CVD increased at all combinations, with an indication for synergism for some CVD subtypes. ${ }^{7-16}$ For example, where high SBP is an important risk factor for CVD in people with and without diabetes and irrespective of levels of BMI, ${ }^{9}$ it may be more strongly related to the risk of CVD at lower levels at TC. ${ }^{7}$ Similarly, smoking seemed to exacerbate the impact of high SBP on the risk of haemorrhagic stroke $\mathrm{e}^{10}$ and that of BMI, TC and high-density lipoprotein cholesterol on the risk of CHD. ${ }^{11} 12$ Hence, effective strategies that target combinations of specific risk factors, such as smoking cessation and weight loss 

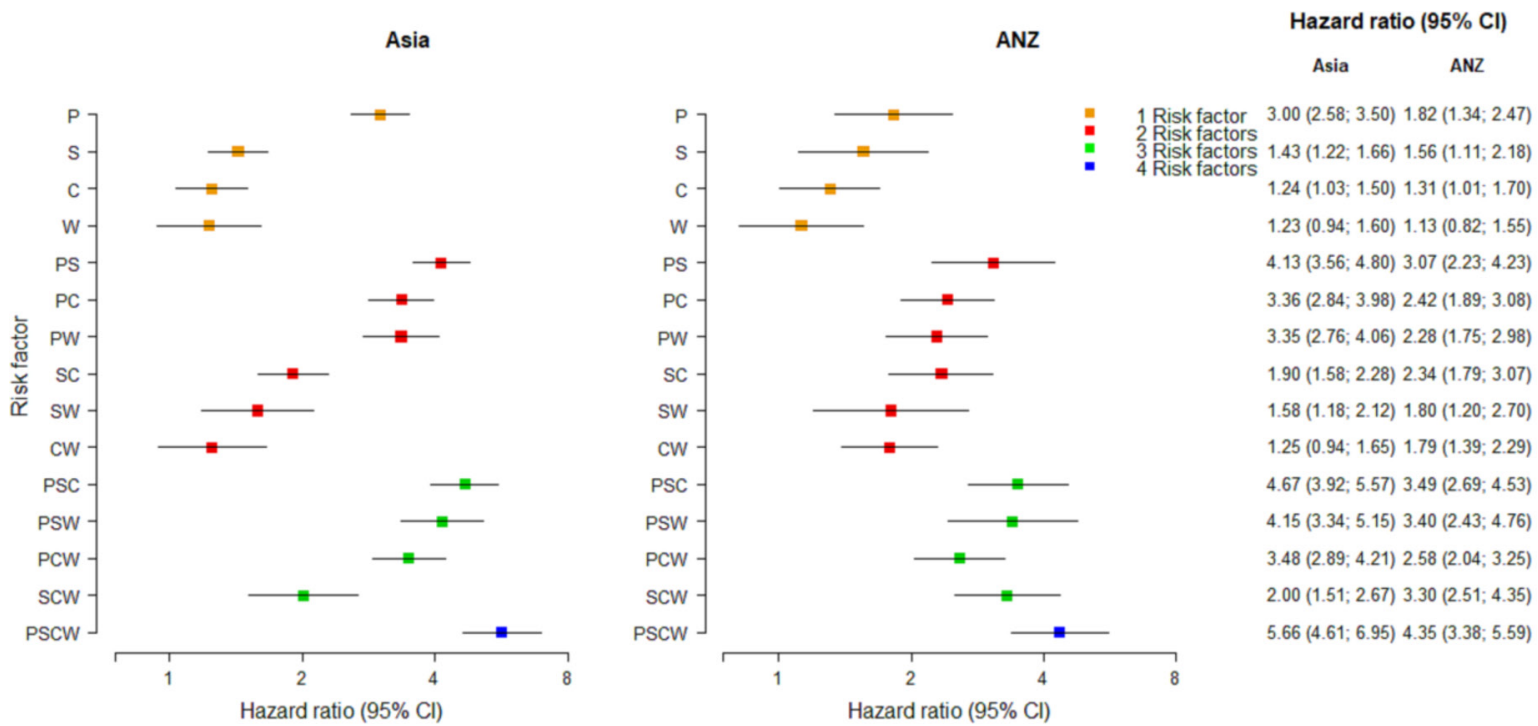

Figure $1 \mathrm{HRs}$ and 95\% Cls for incident cardiovascular disease associated with risk factors and risk factor clusters by region. Analyses are adjusted for age, and stratified by sex and study. Individuals without any elevated risk factor were the reference group. ANZ, Australia and New Zealand; P, high blood pressure; S, current smoking; C, high total cholesterol (TC), W, high body mass index (BMI). High blood pressure was defined as systolic blood pressure $\geq 140 \mathrm{~mm} \mathrm{Hg}$ or diastolic blood pressure $\geq 90 \mathrm{~mm}$ $\mathrm{Hg}$, high TC was defined as a TC level $\geq 5.2 \mathrm{mmol} / \mathrm{L}$ and high BMI was defined as a BMl $\geq 25 \mathrm{~kg} / \mathrm{m}^{2}$.

or blood pressure reduction, could have a greater impact than anticipated on reducing the burden of CVD.

The major shift in causes of death and disability from infectious diseases to non-communicable diseases and increases in life expectancy seen over the past decades pose major challenges on the capacities of health systems globally. These challenges are most profound in low-income and middle-income countries where the burden of CVD is the largest, competing health threats are still present and resources are most limited. ${ }^{22}$ Prevention of CVD through targeting its major modifiable risk factors is arguably the most cost-effective way to reduce the burden of CVD. From the public health perspective, our findings indicate that the largest burden of CVD is attributable to elevated blood pressure and smoking, suggesting that interventions on curbing smoking habits and managing blood pressure levels could have major benefits in terms of reducing the burden of CVD worldwide. However, local contexts need to be considered. Taking smoking, for example, implementing effective smoking bans, raising taxes and the price of tobacco have been effective ways to reduce tobacco use in low-income and middle-income countries. $^{23}$ In contrast, bans on advertising in the mass media to denormalise smoking and behavioural interventions at the individual level are current strategies to reduce the smoking prevalence in high-income countries, where bans on smoking in public places have largely been implemented. Reduction in dietary salt intake is another major strategy to avert the burden of elevated blood pressure; such strategies need to be tailored to the national situation given substantial differences in dietary habits globally. The risk factor clusters with overweight did not rank as high as anticipated. The relatively low PAFs found in our study may be due to the lower prevalence of overweight some decades ago, when the measurements of BMI were done. Since then, the prevalence of overweight and obesity has dramatically increased globally. While further follow-up of existing cohorts and new cohorts are needed to monitor the obesity epidemic and the evolution of the relative risks, contemporary information on the burden of the risk factors and their clustering should become available to local authorities when trying to target their own needs and priorities. Yet, surveillance of the prevalence of risk factor clusters is not available for many countries.

Strengths of this study include its large sample size, prospective design and the inclusion of studies among diverse populations across the Asia-Pacific region. Some limitations of this study need to be acknowledged. First, despite the large sample size, we did not have sufficient CVD events to allow for reliable quantification of associations between risk factor clusters and the risk of major subtypes of CVD, such as CHD and stroke, or sex-specific effects within regions. However, CHD and stroke share many of the same risk factors, and preventive strategies to target clusters are likely to be beneficial in preventing both outcomes in both sexes and across regions. While the number of participants from Asian cohorts was greater than from ANZ cohorts, the number of CVD events, and associated statistical power, was broadly similar between regions. Next, most cohorts from APCSC were initiated around 20 years ago and one might question its suitability 
Table 2 HRs (95\% Cls), prevalence and population attributable fractions (PAFs) for incident cardiovascular disease associated with risk factors and risk factor clusters by sex and region

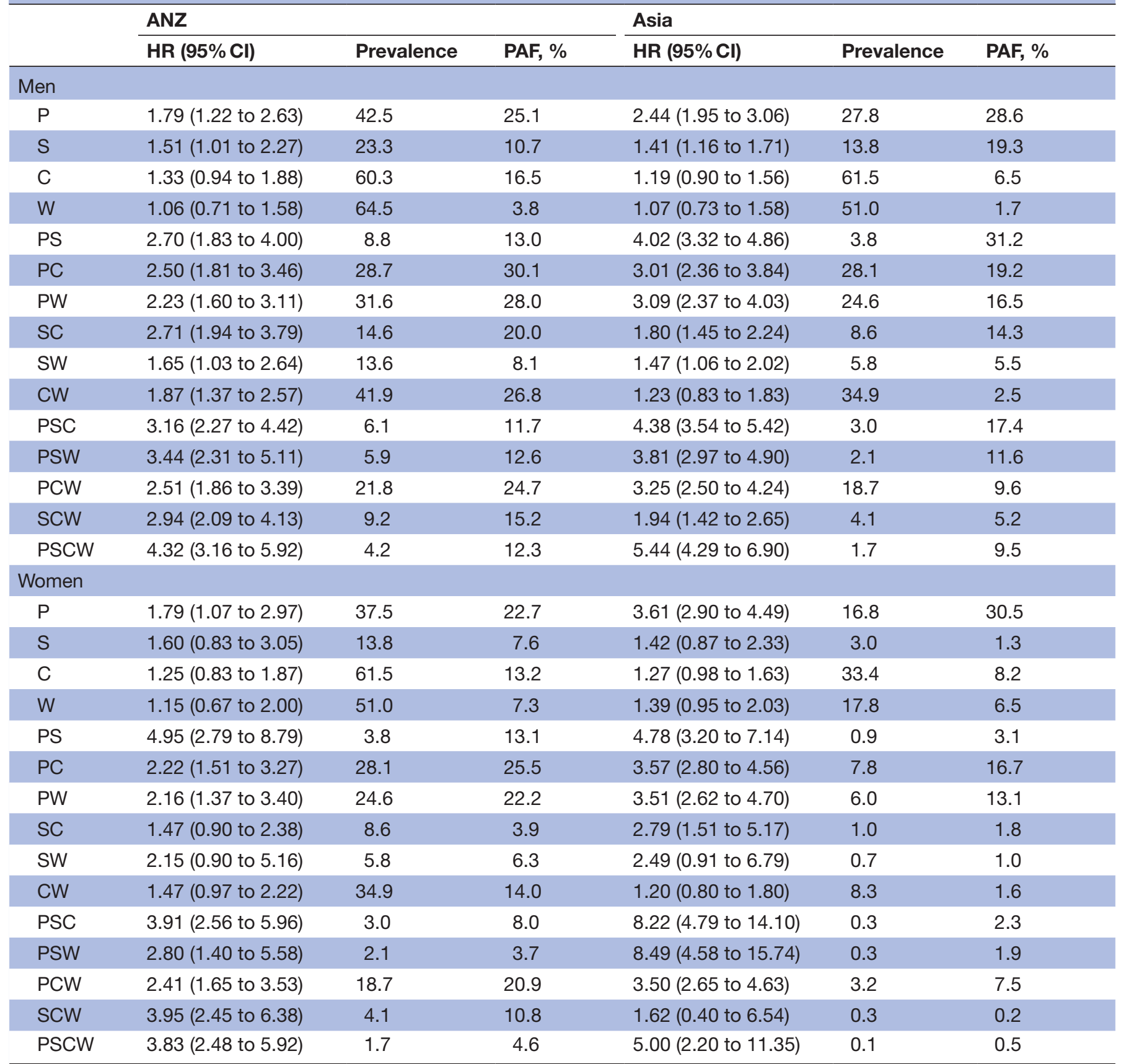

HRs are adjusted for age and stratified by study. Individuals without any elevated risk factor were the reference group. Combinations of risk factors were not mutually exclusive in calculating the prevalence and population attributable fractions. ANZ, Australia and New Zealand; P, high blood pressure; S, current smoking; C, high total cholesterol (TC); W, high body mass index (BMI). High blood pressure was defined as systolic blood pressure $\geq 140 \mathrm{~mm} \mathrm{Hg}$ or diastolic blood pressure $\geq 90 \mathrm{~mm} \mathrm{Hg}$, high TC was defined as a TC level $\geq 5.2 \mathrm{mmol} / \mathrm{L}$ and high BMI was defined as a BMI $\geq 25 \mathrm{~kg} / \mathrm{m}^{2}$.

to address current cardiovascular profiles, given the well-recognised epidemiological transition during the past few decades in Asia. However, the main purpose of this study was to evaluate the aetiological relationships of clusters on risk of CVD, which are less likely to change over time. The historical nature of the data also precluded reliable analysis of clusters involving diabetes, which is a much commoner risk factor in current times. Data on prediabetes were also not available. Finally, ethnicity was not recorded in all studies. However, where we know it, less than $0.5 \%$ of participants in Australia and New Zealand had an Asian ancestry. Hence, we feel that domicile is a reasonable proxy for ethnicity in our data. 

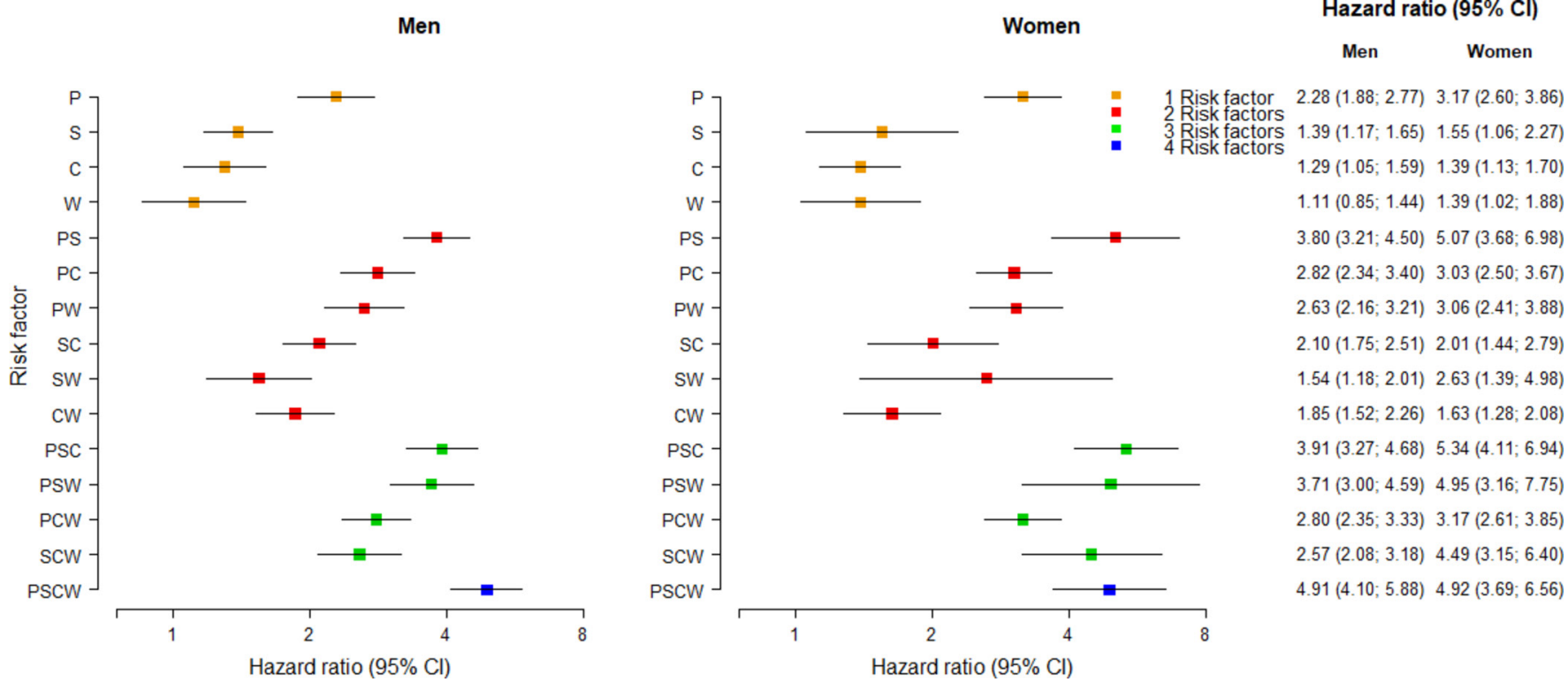

Figure 2 HRs and 95\% Cls for incident cardiovascular disease associated with risk factors and risk factor clusters by sex. Conversions as in figure 1.

In conclusion, clusters of major modifiable risk factors act similarly on the risk of CVD in Asian and Caucasian populations. Risk factor clusters including elevated blood pressure were associated with the highest excess risk of CVD.

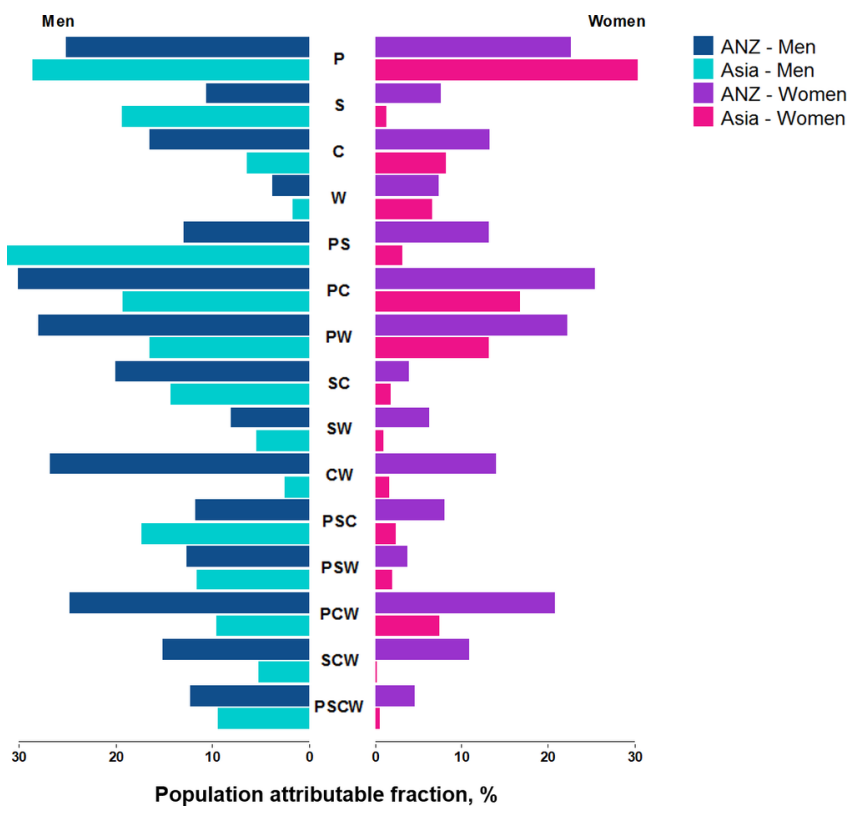

Figure 3 Population attributable fractions of risk factors and risk factor clusters for cardiovascular disease by sex and region. ANZ, Australia and New Zealand; P, high blood pressure; S, current smoking; C, high total cholesterol (TC); $\mathrm{W}$, high body mass index (BMI). High blood pressure was defined as systolic blood pressure $\geq 140 \mathrm{~mm} \mathrm{Hg}$ or diastolic blood pressure $\geq 90 \mathrm{~mm} \mathrm{Hg}$. High TC was defined as a TC level $\geq 5.2 \mathrm{mmol} / \mathrm{L}$. High BMl was defined as a $\mathrm{BMI} \geq 25 \mathrm{~kg} / \mathrm{m}^{2}$. Combinations of risk factors were not mutually exclusive.
Author affiliations

${ }^{1}$ George Institute for Global Health, University of Oxford, Oxford, UK

${ }^{2}$ Julius Center for Health Sciences and Primary Care, University Medical Center Utrecht, Utrecht, The Netherlands

${ }^{3}$ The First Hospital of Jilin University, Changchun, China

${ }^{4}$ School of Public Health, University of Hong Kong, Hong Kong, China

${ }^{5}$ Yonsei University College of Medicine, Seoul, Republic of Korea

${ }^{6} \mathrm{JC}$ School of Public Health and Primary Care, Faculty of Medicine, The Chinese University of Hong Kong, Hong Kong, China

${ }^{7}$ Department of Epidemiology and Public Health, Kyushu University, Fukuoka, Japan ${ }^{8}$ School of Population Health, University of Western Australia, Perth, Western Australia, Australia

${ }^{9}$ Department of Epidemiology, Johns Hopkins University, Baltimore, Maryland, USA

${ }^{10}$ The George Institute for Global Health, University of New South Wales, Sydney, NSW, Australia

Acknowledgements We acknowledge APCSC Executive Committee members and thank principal collaborators in APCSC.

Collaborators APCSC Executive Committee: X. Fang, D.F. Gu, R. Huxley, Y. Imai, H.C. Kim, T.H. Lam, W.H. Pan, A. Rodgers, I. Suh, H. Ueshima, M. Woodward. Participating Studies and Principal Collaborators in APCSC: Aito Town: A. Okayama H. Ueshima; H.Maegawa; Akabane: M. Nakamura, N. Aoki; Anzhen02: Z.S. Wu; Anzhen: C.H. Yao, Z.S. Wu; Australian Longitudinal Study of Aging: Mary Luszcz; Australian National Heart Foundation: T.A. Welborn; Beijing Aging: Z. Tang; Beijing Steelworkers: L.S. Liu, J.X. Xie; Blood Donors' Health: R. Norton, S. Ameratunga, S. MacMahon, G. Whitlock; Busselton: M.W. Knuiman; Canberra- Queanbeyan: H. Christensen; Capital Iron and Steel Company: X.G. Wu; CISCH: J. Zhou, X.H. Yu; Civil Service Workers: A. Tamakoshi; CVDFACTS: W.H. Pan; East Beijing: Z.L. Wu, L.Q. Chen, G.L. Shan; Electricity Generating Authority of Thailand: P. Sritara; Fangshan: D.F. Gu, X.F. Duan; Fletcher Challenge: S. MacMahon, R. Norton, G. Whitlock, R. Jackson; Guangzhou: Y.H. Li; Guangzhou Occupational: T.H. Lam, C.Q. Jiang; Hisayama: T Ninomiya, J Hata, Y Hirakawa; Hong Kong: J. Woo, S.C. Ho; Huashan: Z. Hong, M.S. Huang, B. Zhou; Kinmen: J.L. Fuh; Konan: H. Ueshima, Y. Kita, S.R. Choudhury; KMIC: I. Suh, S.H. Jee, I.S. Kim; Melbourne: G.G. Giles; Miyama: T. Hashimoto, K. Sakata; Newcastle: A. Dobson; Ohasama: Y. Imai, T. Ohkubo, A. Hozawa; Perth: K. Jamrozik, M.W. Knuiman, M. Hobbs, R. Broadhurst; Saitama: K. Nakachi; Seven Cities: X.H. Fang, S.C. Li, Q.D. Yang; Shanghai Factory Workers: Z.M. Chen; Shibata: H. Tanaka; Shigaraki Town: Y. Kita, A. Nozaki, H. Ueshima; Shirakawa: H. Horibe, Y. Matsutani, M. Kagaya; Singapore Heart: K. Hughes, J. Lee; Singapore NHS92: D. Heng, S.K. Chew; Six Cohorts: B.F. Zhou, H.Y. Zhang; Tanno/Soubetsu: K. Shimamoto, S. Saitoh; Tianjin: Z.Z. Li, H.Y. Zhang; Western Australia AAA Screenees: P. Norman, K. Jamrozik; Xi'an: Y. He, T.H. Lam; Yunnan: S.X. Yao. 
Contributors SAEP, XW, MLB, IV and MW conceived the study. T-HL, HCK, SH, TN, MK and MW retrieved the study data, along with other principal collaborators in the Asia Pacific Cohort Studies Collaboration. SAEP and XW did the statistical analyses and drafted the manuscript. SAEP, XW, T-HL, HCK, SH, TN, MK, IV, MLB and MW participated in data interpretation, made important revisions to the draft manuscript and read and approved the final manuscript.

Funding This research received no specific grant from any funding agency in the public, commercial or not-for-profit sectors.

Competing interests None declared.

Patient consent Not required.

Provenance and peer review Not commissioned; externally peer reviewed.

Data sharing statement № additional data available.

Open Access This is an Open Access article distributed in accordance with the Creative Commons Attribution Non Commercial (CC BY-NC 4.0) license, which permits others to distribute, remix, adapt, build upon this work non-commercially, and license their derivative works on different terms, provided the original work is properly cited and the use is non-commercial. See: http://creativecommons.org/ licenses/by-nc/4.0/

(c) Article author(s) (or their employer(s) unless otherwise stated in the text of the article) 2018. All rights reserved. No commercial use is permitted unless otherwise expressly granted.

\section{REFERENCES}

1. Murray CJ, Vos T, Lozano R, et al. Disability-adjusted life years (DALYs) for 291 diseases and injuries in 21 regions, 1990-2010: a systematic analysis for the Global Burden of Disease Study 2010. Lancet 2012;380:2197-223.

2. Yusuf $S$, Hawken $S$, Ounpuu $S$, et al. Effect of potentially modifiable risk factors associated with myocardial infarction in 52 countries (the INTERHEART study): case-control study. Lancet 2004;364:937-52.

3. O'Donnell MJ, Xavier D, Liu L, et al. Risk factors for ischaemic and intracerebral haemorrhagic stroke in 22 countries (the INTERSTROKE study): a case-control study. Lancet 2010;376:112-23.

4. Murray CJ, Barber RM, Foreman KJ, et al. Global, regional, and national disability-adjusted life years (DALYs) for 306 diseases and injuries and healthy life expectancy (HALE) for 188 countries, 1990-2013: quantifying the epidemiological transition. Lancet 2015;386:2145-91.

5. Lim SS, Vos T, Flaxman AD, et al. A comparative risk assessment of burden of disease and injury attributable to 67 risk factors and risk factor clusters in 21 regions, 1990-2010: a systematic analysis for the Global Burden of Disease Study 2010. Lancet 2012;380:2224-60.

6. Yusuf HR, Giles WH, Croft JB, et al. Impact of multiple risk factor profiles on determining cardiovascular disease risk. Prev Med 1998:27:1-9.

7. Rodgers A, Lam TH, Suh I, et al. Joint effects of systolic blood pressure and serum cholesterol on cardiovascular disease in the Asia Pacific region. Circulation 2005;112:3384-90.
8. Kengne AP, Patel A, Barzi F, et al. Cholesterol, diabetes and major cardiovascular diseases in the Asia-Pacific region. Diabetologia 2007;50:2289-97.

9. Kengne AP, Patel A, Barzi F, et al. Systolic blood pressure, diabetes and the risk of cardiovascular diseases in the Asia-Pacific region. $J$ Hypertens 2007;25:1205-13.

10. Nakamura K, Barzi F, Lam TH, et al. Cigarette smoking, systolic blood pressure, and cardiovascular diseases in the Asia-Pacific region. Stroke 2008;39:1694-702.

11. Nakamura K, Barzi F, Huxley R, et al. Does cigarette smoking exacerbate the effect of total cholesterol and high-density lipoprotein cholesterol on the risk of cardiovascular diseases? Heart 2009;95:909-16.

12. Huxley RR, Nakamura K, Lam TH, et al. Impact of cigarette smoking on the relationship between body mass index and coronary heart disease: a pooled analysis of 3264 stroke and $2706 \mathrm{CHD}$ events in 378579 individuals in the Asia Pacific region. BMC Public Health 2009:9:9-294.

13. Kengne AP, Nakamura K, Barzi F, et al. Smoking, diabetes and cardiovascular diseases in men in the Asia Pacific region. $J$ Diabetes 2009;1:173-81.

14. Murakami Y, Huxley RR, Lam TH, et al. Diabetes, body mass index and the excess risk of coronary heart disease, ischemic and hemorrhagic stroke in the Asia Pacific Cohort Studies Collaboration. Prev Med 2012;54:38-41.

15. Tsukinoki R, Murakami Y, Huxley R, et al. Does body mass index impact on the relationship between systolic blood pressure and cardiovascular disease?: meta-analysis of 419488 individuals from the Asia pacific cohort studies collaboration. Stroke 2012;43:1478-83.

16. Hirakawa $\mathrm{Y}$, Lam TH, Welborn $\mathrm{T}$, et al. The impact of body mass index on the associations of lipids with the risk of coronary heart disease in the Asia Pacific region. Prev Med Rep 2016;3:79-82.

17. Woodward M, Huxley R, Ueshima $\mathrm{H}$, et al. The Asia pacific cohort studies collaboration: a decade of achievements. Glob Heart 2012;7:343-51.

18. World Health Organization. Physical status: the use and interpretation of anthropometry. Geneva, 1995.

19. The fifth report of the Joint National Committee on Detection, Evaluation, and Treatment of High Blood Pressure (JNC V). Arch Intern Med 1993;153:154-83.

20. Haymes RC. National Cholesterol Education Program (NCEP) Expert Panel on Detection, Evaluation, and Treatment of High Blood Cholesterol in Adults (Adult Treatment Panel III). Third Report of the National Cholesterol Education Program (NCEP) Expert Panel on Detection, Evaluation, and Treatment of High Blood Cholesterol in Adults (Adult Treatment Panel III) final report. Circulation 2002;106:3143-421.

21. Woodward M. Epidemiology: study design and data analysis. 3rd edn. Boca Raton: CRC Press, 2014

22. Huxley RR, Hirakawa Y, Hussain MA, et al. Age- and sex-specific burden of cardiovascular disease attributable to 5 major and modifiable risk factors in 10 asian countries of the western pacific region. Circ J 2015;79:1662-74.

23. Hu TW, Mao Z, Shi J, et al. The role of taxation in tobacco control and its potential economic impact in China. Tob Control 2010;19:58-64. 